\title{
DÜBLIN
}

Technological University Dublin

ARROW@TU Dublin

2012-11-12

\section{Circularly Polarized Terminal Antennas for Emerging Wireless Systems}

\author{
Max Ammann \\ Technological University Dublin, max.ammann@tudublin.ie \\ Xiulong Bao \\ Technological University Dublin, xiulong.bao@tudublin.ie \\ Adam Narbudowicz \\ Technological University Dublin
}

Follow this and additional works at: https://arrow.tudublin.ie/ahfrccon

Part of the Systems and Communications Commons

\section{Recommended Citation}

Ammann, M., Bao, X. L., \& Narbudowicz, A. (2012) Circularly Polarized Terminal Antennas for Emerging Wireless Systems, LAPC - Loughborough Antennas \& Propagation Conference, Loughborough, UK, pp. 1-5, 12/11/2012. doi:10.1109/LAPC.2012.6402946

This Conference Paper is brought to you for free and open access by the Antenna \& High Frequency Research Centre at ARROW@TU Dublin. It has been accepted for inclusion in Conference Papers by an authorized administrator of ARROW@TU Dublin. For more information, please contact arrow.admin@tudublin.ie, aisling.coyne@tudublin.ie, gerard.connolly@tudublin.ie. Funder: SFI 


\title{
Circularly Polarized Terminal Antennas for Emerging Wireless Systems
}

\author{
Max J. Ammann, X. L Bao and Adam Narbudowicz \\ Antenna \& High Frequency Research Centre \\ Dublin Institute of Technology, \\ Kevin Street, Dublin 8, Ireland \\ max.ammann@dit.ie \\ xbao@dit.ie \\ adam.narbudowicz@mydit.ie
}

\begin{abstract}
Several types of omni-directional Circularly Polarized (CP) antennas are presented, which are employed by three different types of feedlines: Coplanar Waveguide $(C P W)$ fed, Microstrip fed, and Differential-fed, to achieve omni-directional CP performances. The Dual-frequency Omni-directional CP antenna is proposed by using slot and inductor embedded into radiated patches. These omnidirectional CP antennas have potential application on GPS, WLAN and RFID systems.
\end{abstract}

\section{INTRODUCTION}

With the increased demand for wireless network systems, satellite communications systems and global navigation satellite systems, circularly polarized antennas have become more attractive to engineering designers [1-3]. Circular polarization (CP) combats Faraday rotation and can significantly reduce multipath fading effects and polarization mismatch loss experienced in linear systems. Many techniques have been reported to improve the performance of $\mathrm{CP}$ antennas, in particular with improvements in bandwidth, gain and beamwidth. The antenna bandwidth and gain of a rhombic loop antenna were increased by using coupling strips [4]. A combined structure with two bowtie patches and two electric dipoles were used to provide wide beamwidth CP [5]. A reconfigurable patch antenna was introduced to obtain dualsense CP characteristics [6].

In recent years, omni-directional $\mathrm{CP}$ antennas have been presented in the literature using various techniques [7-11]. One method is to use back-to-back microstrip patches which are fed by coplanar waveguide (CPW) [7]. The combined radiation from the patches provide omni-directional $\mathrm{CP}$ performance in one plane. Another technique for low-profile application uses a top-loaded cylindrical monopole structure and four printed arc-shaped dipoles providing omni-directional $\mathrm{CP}$ in the azimuth plane [10]. Additionally, a conical skirt monopole antenna with a polarizer was presented [11]. The polarizer consists of a series of $45^{\circ}$ tilted parasitic strips embedded into the surface of the cylinder dielectric. The polarizer can converts the wave from linear to circular polarization. Hence, omni-directional CP performance is achieved. More recently, a zero-order resonator (ZOR) loaded with arc-shaped subs along the patch was employed to achieve CP omni-directional performance $[12,13]$.

In this paper, omni-directional $\mathrm{CP}$ antennas which are fed using various feed techniques are reported.

\section{SINGLE FREQUENCY OMNIDIRECTIONAL CP ANTENNA DESIGN}

In order to be integrated successfully into various wireless systems, omni-directional CP antennas need to be fed using various feedlines, such as $\mathrm{CPW}$, microstrip and balanced lines. These feedline types are presented for both single and dualband omni-directional antennas. In this work, the substrate used was Taconic RF-35 with a relative permittivity 3.47 , a loss tangent 0.0018 and thickness of $1.57 \mathrm{~mm}$.

\section{A. CPW-Fed Omnidirectional CP Antenna Design}

The antenna consists of a two layer substrate and three layers of metallisation: the two outer layers forming the patches, the middle layer forming the ground plane with CPW feed [14]. The patches are connected by a copper conducting strip as shown in Fig. 1 (a). The structure was simulated by using CST MWS. The parameters of the optimised antenna are as follows $(\mathrm{mm}): l_{a}=51.2, l_{b}=49.6, W_{s}=14, S=55.8, \Delta_{a}=2.3$, $\Delta_{b}=3.1, \Delta_{f}=19.5, \Delta_{t}=2, l_{t}=12, \Delta_{s}=1$.

Fig.1 (b) shows that the measured and simulated $\mathrm{S}_{11}$ are in agreement. The measured $\mathrm{S}_{11}$ is $<-10 \mathrm{~dB}$ from $1.579 \mathrm{GHz}$ to $1.613 \mathrm{GHz}$ has a $2.1 \%$ impedance bandwidth. RHCP is achieved $(\mathrm{AR}<\sim 4 \mathrm{~dB})$ in the band $1.593-1.601 \mathrm{GHz}$, providing an omnidirectional $\mathrm{CP}$ bandwidth of $7 \mathrm{MHz}(0.4$ $\%)$. The measured and simulated AR against angle at 1.596 $\mathrm{GHz}$ is shown in Fig. 2 (a).

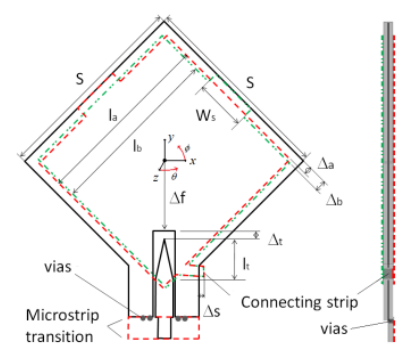

(a)

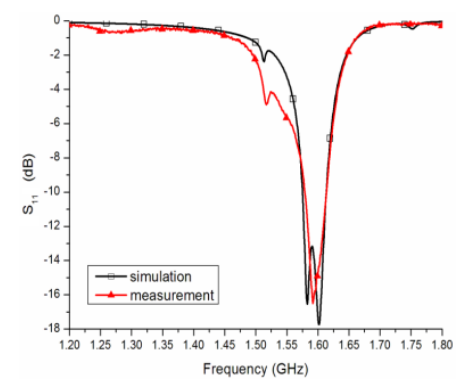

(b)
Fig.1(a) Configuration of the proposed CPW-fed omnidirectional CP antenna and (b) the simulated and measured results 


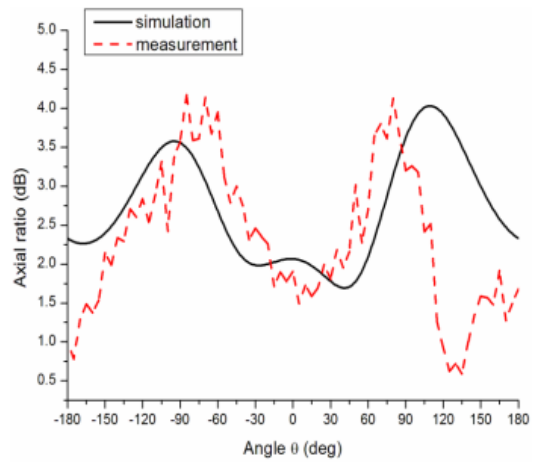

(a)

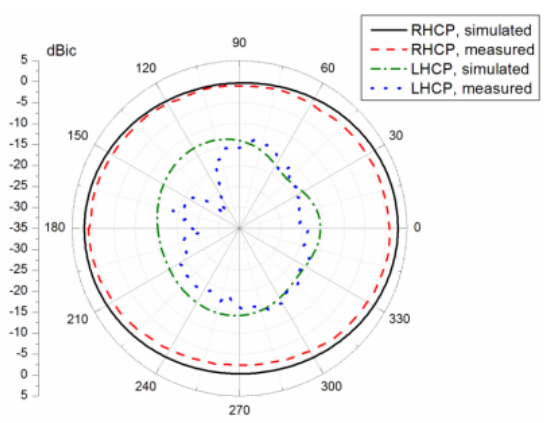

(b)

Fig. 2(a) AR against angle and (b) patterns at $1.576 \mathrm{GHz}$

The AR is better than $\sim 4 \mathrm{~dB}$ over the full $360^{\circ}$ and generally better than $3.5 \mathrm{~dB}$. The measured peak gain is $1.1 \mathrm{dBic}$, with a variation of $\sim 3 \mathrm{~dB}$ in the $\mathrm{Phi}=0^{\mathrm{O}}$ plane. The cross-polar isolation is better than $13 \mathrm{~dB}$ as shown in Fig. 2 (b).

\section{B. Microstrip-Fed Omnidirectional CP Antenna}

Three different microstrip-fed antenna geometries are proposed in Figs 3-5 which are printed on two-layer substrates. An omni-directional circular patch arrangement is shown in Fig 3 where the top substrate size is $W_{l} \times L_{l}$ and the lower one is $W_{2} \times L_{2}$. Two stubs at $45^{\circ}$ with respect to feedline are placed on both patches. A via of radius $r_{n}$ is connected between the top and bottom patch located at $(x, y)$, where $(0,0)$ corresponds to the centre of the patch. In order to isolate the via from the groundplane, a circular slot of radius $r_{s}$ is appropriately located on the centre plane. By adjusting key parameters, such as stubs $W_{l}$ and $L_{l}$ and the via location, an omni-directional CP performance is realised. The parameter values are tabulated in Table 1.

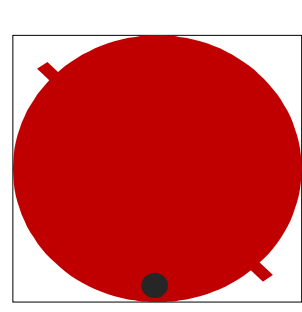

Fig. 3. Geometry of the circular patch

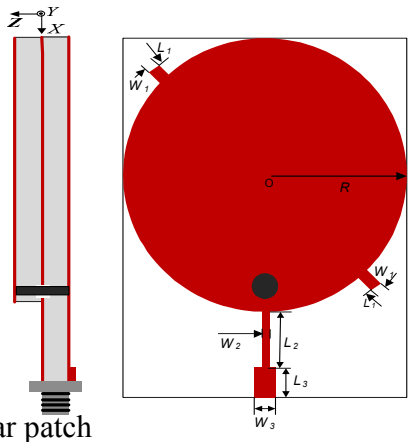

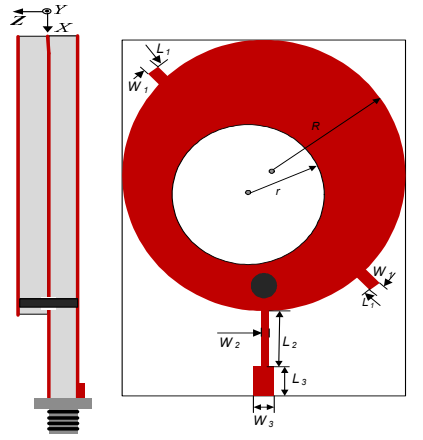

Fig.4. Geometry of the circular patch with slot circular
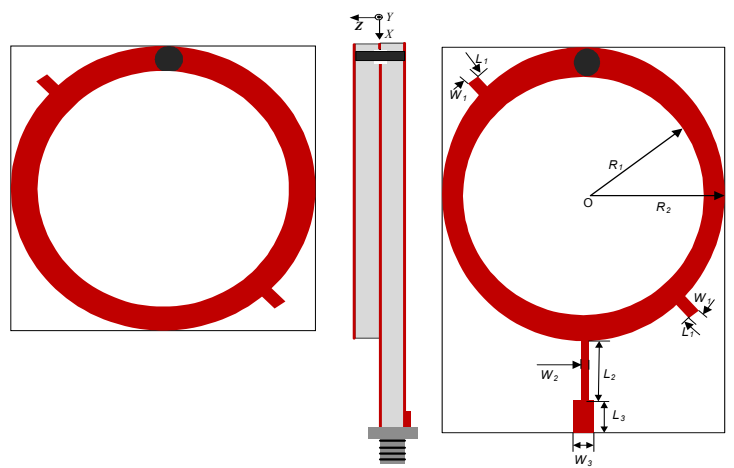

Fig. 5. Geometry of the annual ring patch

Table 1. Parameters of Microstrip-fed antennas

\begin{tabular}{|c|c|c|c|}
\hline Parametrers (mm) & $\begin{array}{c}\text { Circular } \\
\text { Patch }\end{array}$ & $\begin{array}{c}\text { Circular Patch } \\
\text { With circular Slot }\end{array}$ & $\begin{array}{l}\text { Annular } \\
\text { Ring } \\
\text { Patch }\end{array}$ \\
\hline$R$ & 28.7 & 25.0 & - \\
\hline$r$ & - & 10.7 & - \\
\hline R1 & - & - & 20.55 \\
\hline$R 2$ & - & - & 15.85 \\
\hline$W 1 / L 1$ & $2 / 3.5$ & $2 / 3.5$ & $2 / 3.5$ \\
\hline$W 2 / L 2$ & $2 / 10$ & $0.6 / 12$ & $0.6 / 12.46$ \\
\hline W3/L3 & $3 / 7$ & $3 / 2$ & $3 / 2$ \\
\hline Via location & $(22,0)$ & $(18,0)$ & $(-17.8,0)$ \\
\hline Origin of Slot & & $(2.7,2.7)$ & - \\
\hline Substrate Size & $\begin{array}{l}62 \times 62 \\
70 \times 62\end{array}$ & $\begin{array}{l}55 \times 50 \\
65 \times 50\end{array}$ & $\begin{array}{l}42 \times 42 \\
65 \times 42\end{array}$ \\
\hline
\end{tabular}

Fig. 6 shows the simulated $S_{11}$ for the three antennas. It is noted that the impedance bandwidth is increased as the dimension of antenna is increased. The three antennas provide an axial-ratio (AR) less than $3 \mathrm{~dB}$ in the $\mathrm{YoZ}$ plane at 
$1.575 \mathrm{GHz}$, as shown in Fig. 7. The annular-ring patch is the smallest geometry and is $44 \%$ less than the circular patch antenna. Fig. 8 illustrates the radiation patterns at $1.575 \mathrm{GHz}$ for the YoZ plane. As seen, RHCP pattern in the YoZ plane is omni-directional.

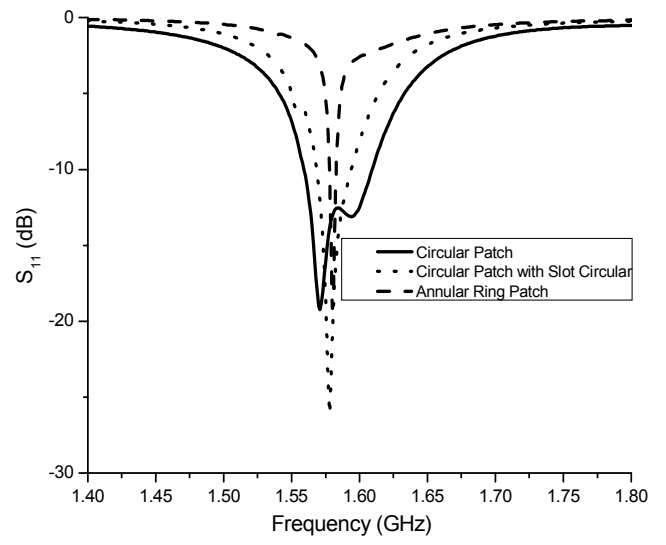

Fig.6 The simulated $\mathrm{S}_{11}$ for microstrip-fed omni-directional $\mathrm{CP}$ antennas

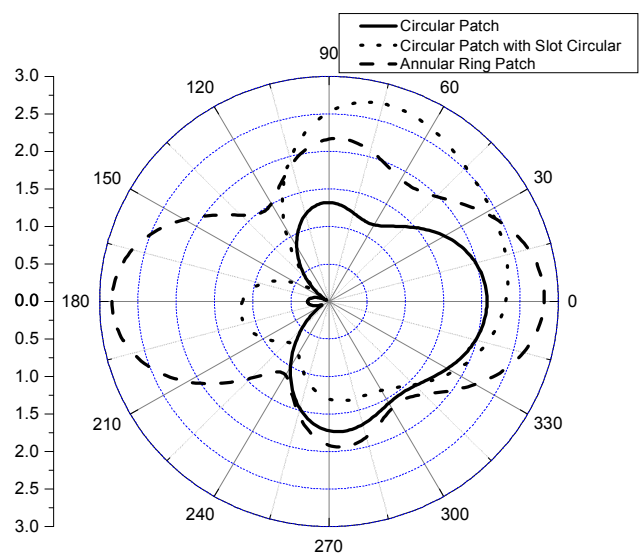

Fig. 7. Axial-ratio for the microstrip-fed patch antennas in the YoZ plane

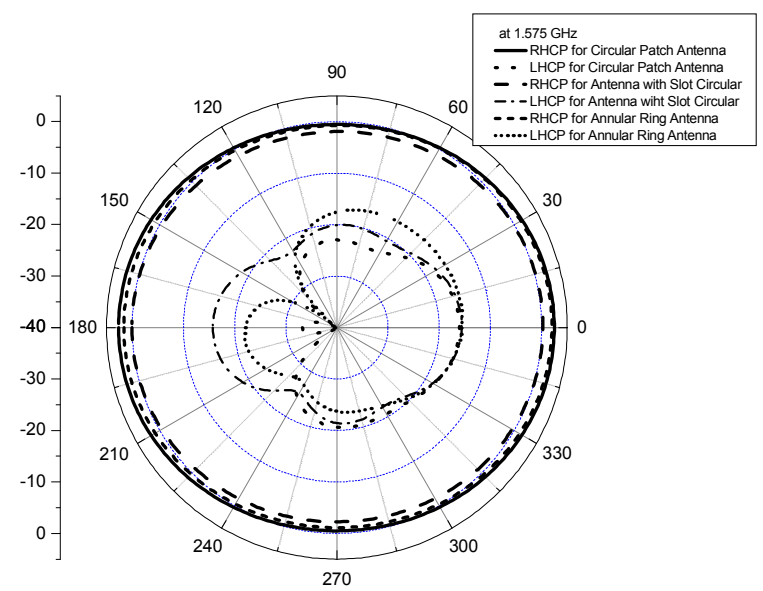

Fig. 8 Radiation patterns in the YoZ plane

\section{Differentially-fed Omnidirectional CP Antenna}

The proposed antenna again consists of a two layer substrate with three metallisation layers. The central ground plane measures $L_{X} \mathrm{X} L_{g}$ and the top and bottom layers have the same square patch structure with a 45 degree slot located centrally, which excites two nearly degenerate resonant modes and achieve CP performance. The configuration is shown in Fig. 9. The balanced parallel lines present a $300 \Omega$ input impedance. The substrate height is $3.175 \mathrm{~mm}$.

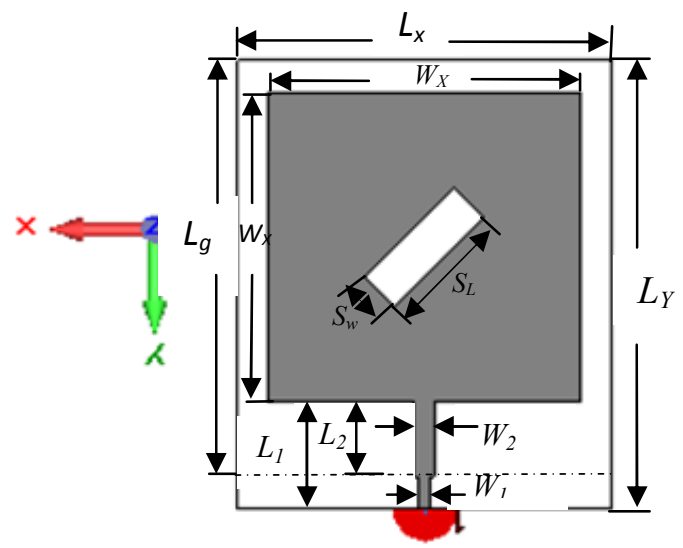

Fig. 9. The configurations of the proposed differentially-fed antenna $L x=35.6 \mathrm{~mm}, L y=42.8 \mathrm{~mm}, L g=37.8 \mathrm{~mm}, S_{L}=12 \mathrm{~mm}, S_{W}=4 \mathrm{~mm}, W x=29.6 \mathrm{~mm}$, $L_{l}=10.2 \mathrm{~mm}, L_{2}=7.2 \mathrm{~mm}, W_{l}=1 \mathrm{~mm}, W_{2}=2 \mathrm{~mm}$

Fig. 10 shows a simulated $\mathrm{S}_{11}$ bandwidth of $70 \mathrm{MHz}$ from $2.374 \mathrm{GHz}$ to $2.444 \mathrm{GHz}$. Fig. 11 displays the AR plotted against azimuthal angle in the $\mathrm{YoZ}$ plane. It is found that $\mathrm{AR}$ bandwidth is $25 \mathrm{MHz}$, from $2.418 \mathrm{GHz}$ to $2.43 \mathrm{GHz}$. Fig 12 shows that the cross-polarization levels are approximately 20 $\mathrm{dB}$ over 360 degrees in the YoZ plane at $2.43 \mathrm{GHz}$.

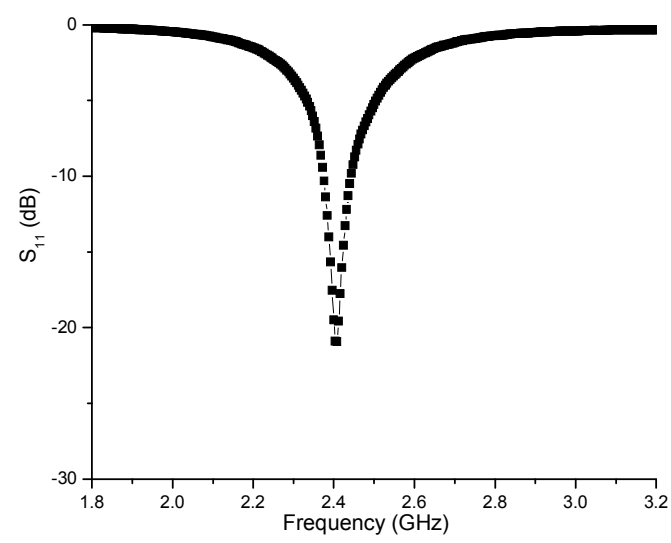

Fig.10. The simulated S11 for the proposed differentially-fed antenna 


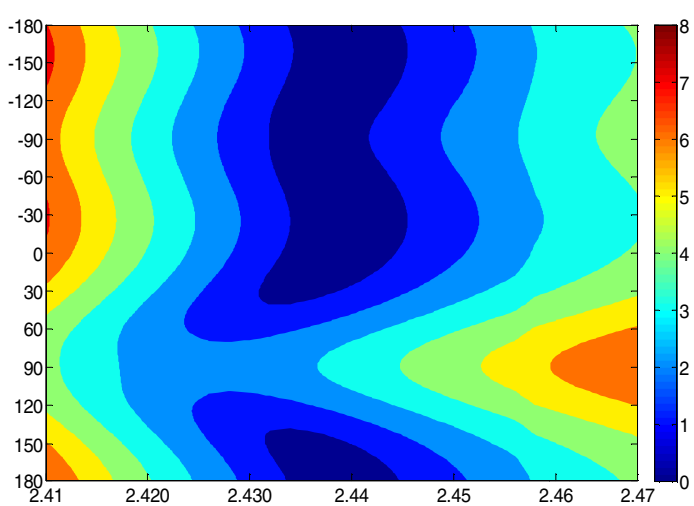

Fig. 11. The axial-ratio values plotted against angle

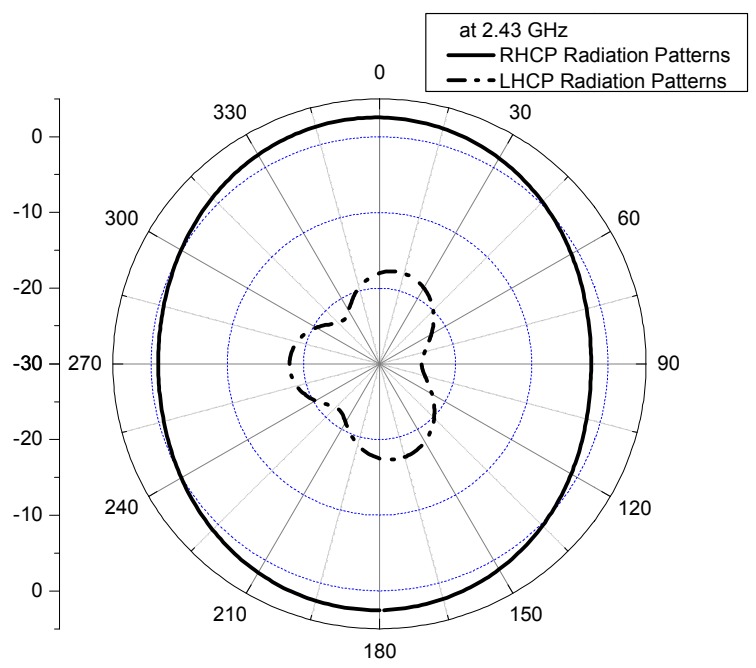

Fig.12. Simulated radiation patterns for the proposed antenna

\section{DUAL-FREQUENCY OMNIDIRECTIONAL CP ANTENNA DESIGN}

Dual-frequency operation was also achieved for the antenna [15] with the addition of slots as shown in Figure 13. The radiators are electromagnetically-coupled to a $50 \Omega \mathrm{CPW}$ located along the diagonal of the patches. The end of the line is triangularly tapered to increase its impedance. The parameter $l_{C P W}$ was optimized to realize best matching. There are two slots cut in each patch, with a $1.5 \mathrm{pF}$ lumped capacitor connected across the centre. The parameter values are shown in Figure 13. The $S_{11}$ is shown in Figure 14. The simulated radiation efficiency is greater than $50 \%$ for both bands. Fig. 15 shows the AR as a function of both angle and frequency. The measured frequency ratio is 1.182. A clear omnidirectional and dual-band pattern can be seen in Fig. 16 (a) and (b). The RHCP gain ranges from $-0.7 \mathrm{dBic}$ to $-4.5 \mathrm{dBic}$ for the upper band and from $-0.7 \mathrm{dBic}$ to $-4 \mathrm{dBic}$ for the lower band.

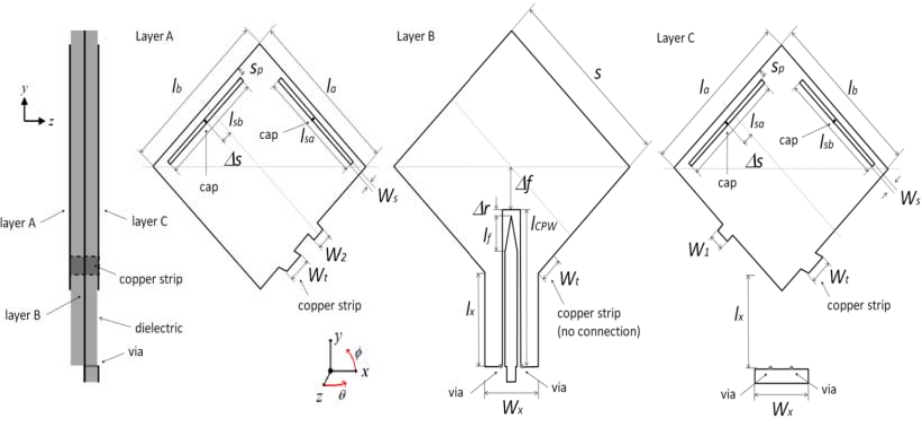

Fig 13. The geometry of the proposed dual-frequency Omnidirectional CP antenna. Parameters: $l_{a}=57 \mathrm{~mm} ; l_{b}=57.1 \mathrm{~mm} ; s_{p}=2.25 \mathrm{~mm} ; l_{s b}=36.8 \mathrm{~mm}$; $l_{s a}=35.8 \mathrm{~mm} ; W_{s}=1.5 \mathrm{~mm} ; \Delta s=3 \mathrm{~mm} ; W_{t}=5.0 \mathrm{~mm} ; \Delta_{f}=14.0 \mathrm{~mm} ;$ $\Delta_{r}=2.0 \mathrm{~mm} ; l_{f}=12.0 \mathrm{~mm} ; l_{c p w}=50.8 \mathrm{~mm} ; W_{X}=20.0 \mathrm{~mm} ; l_{X}=29.7 \mathrm{~mm}$; $s=64 \mathrm{~mm}$

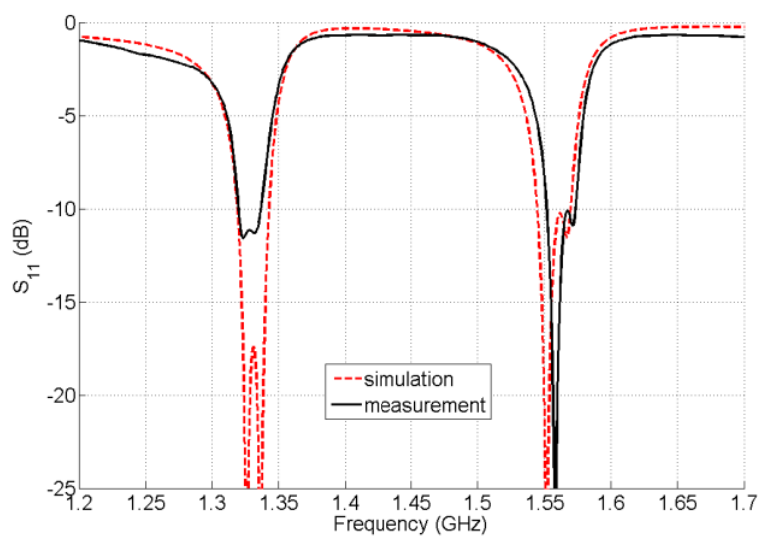

Fig. 14 Simulated and measured results for the dual-frequency omnidirectional CP antenna

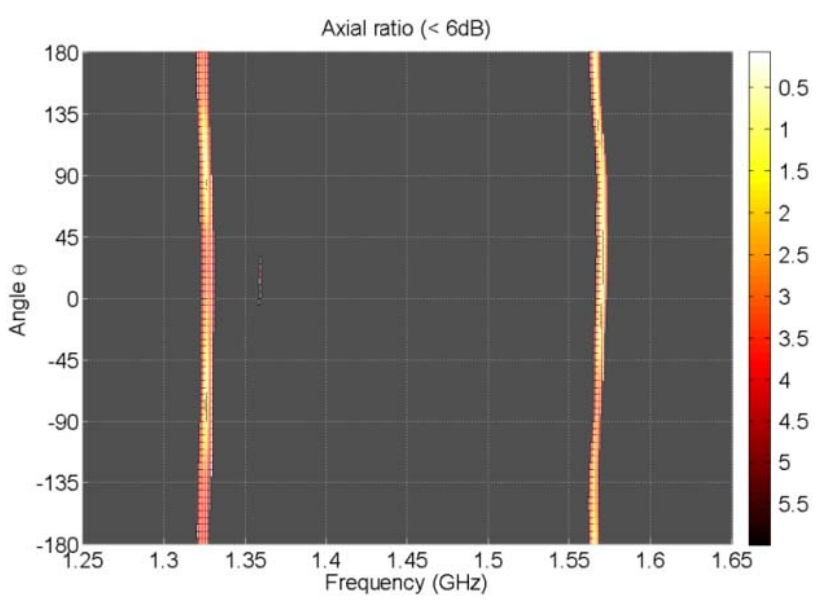

Fig. 15 The measured axial-ratio for the dual-frequency omnidirectional CP antenna 


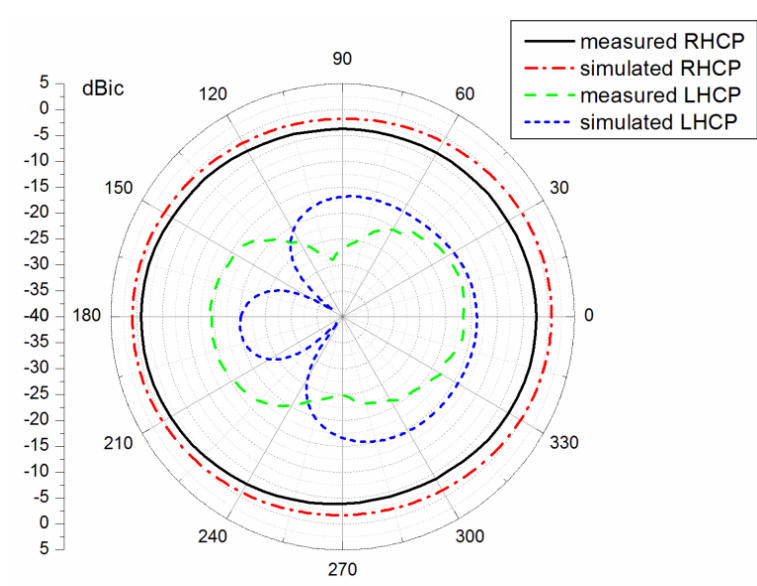

(a)

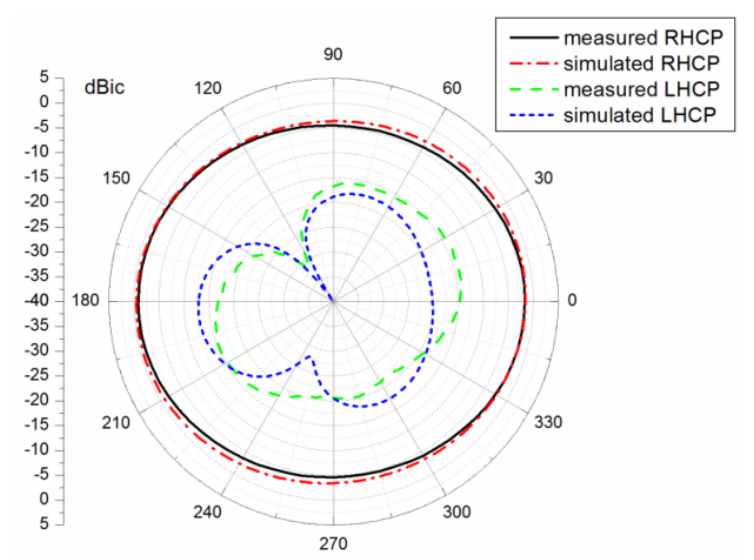

(b)

Fig. 16. (a) Simulated and measured radiation patterns for the low frequency and (b) high frequency.

\section{CONCLUSIONS}

Microstrip patch antennas are shown to provide omnidirectional $\mathrm{CP}$ using various feed techniques with $\mathrm{AR}$ below $\sim 4 \mathrm{~dB}$. For the microstrip-fed geometries, the annularring patch achieves the smallest size. A new technique to control the current distribution by bonding the back-to-back patches and the use of a diagonal CPW shallow inset feed was demonstrated to provide good matching and AR. A differentially-fed antenna is introduced with relatively broadband CP performance. Dual-frequency performance was achieved using lumped capacitor loaded slots which enable the generation of $\mathrm{TM}_{200}$ and $\mathrm{TM}_{020}$ modes.

\section{ACKNOWLEDGMENT}

This publication has emanated from research conducted with the financial support of Science Foundation Ireland under Grant Number 09/SIRG/I1644.

\section{REFERENCES}

[1]. J. M. Baracco, L. Salghetti-Drioli, and P. D. Maagt, AMC Low Profile Wideband Reference Antenna for GPS and GALILEO Systems, IEEE Transactions on Antennas and Propagation, Vol.56, No.8, 2008, pp. 2540-2547.

[2]. L. Boccia, G. Amendola, and G. Di Massa, Performance Evaluation of Shorted Annular Patch Antennas for High-Precision GPS Systems, IET Microwave, Antennas Propagation, Vol.1, No.2, 2007, pp.465-471.

[3]. F. Ferrero, C. Luxey, G. Jacquemod, R. Starai, Dual-band Circularly Polarized Microstrip Antenna for Satellite Applications, IEEE Antennas and Wireless Propagation Letters, Vol.4, 2005, pp.13-15.

[4]. R. L. Li, A. Traille, J. Laskar, M. M. Tentzeris, Bandwidth and Gain Improvement of a Circularly Polarized Dual-Rhombic Loop Antenna, IEEE Antennas and Wireless Propagation Letters, Vol.5, 2006, pp.84-87.

[5]. K. M. Mak, and K. M. Luk, A Circularly Polarized Antenna With Wide Axial Ratio Beamwidth, IEEE Transactions on Antennas and Propagation, Vol. 57, No. 10, 2009, pp.3309-3312.

[6]. J. S. Row, and M. C. Chan, Reconfigurable Circularly-Polarized Patch Antenna With Conical Beam, IEEE Transactions on Antennas and Propagation, Vol. 58, No. 8, 2010, pp.2753-2757.

[7]. United States Patent, Broadband Circularly Polarized Omnidirectional Antenna, April 11, 1972, No. 3656166.

[8]. G. H. Brown, and O. M. Woodward, Circularly-Polarized Omnidirectional Antenna, RCA Rev., Vo. 8, pp.259-269.

[9]. H. Iwasaki, and N. Chiba, Circularly Polarised Back-to-Back Microstrip Antenna with an Omnidirectional Pattern, IEE Proc.-Microw Antennas Propagation, Vol. 146, No. 4, 1999, pp. 277-281.

[10]. F. R. Hsiao, and K. L. Wong, Low-Profile Omnidirectional Circularly Polarized Antenna for Wlan Access Points, Microwave and Optical Technology Letters, Vol. 46, No. 3, 2005, pp.227-231.

[11]. J. M. Fernandez, J. L. Masa-Campos, and M. Sierra-Perez, Circularly Polarized Omnidirectional Millimeter Wave Monopole with Parasitic Strip Elements, Microwave and Optical Technology Letters, Vol. 49, No. 3, 2007, pp.664-668.

[12]. B. C. Park, and J. H. Lee, Omnidirectional Circularly Polarized Antenna Based on Meta Material Transmission Line, IEEE AP-S 2009.

[13]. J. An, G. M. Wang, C. X. Zhang, and H. Y. Zeng, A Compact Omnidirectional Circularly Polarized Microstrip Antenna, Microwave Journal, Vol. 53, No. 12, 2010, pp.82-91.

[14]. A. Narbudowicz, X. L. Bao, and M. J. Ammann, Omnidirectional Circularly-polarised Microstrip Patch Antenna, IET Electronics Letters, Vol. 28, No.11, 2012, pp. $614-615$.

[15]. A. Narbudowicz, X. L. Bao, and M. J. Ammann, Dual-band Omnidirectional Circularly Polarized Antenna, IEEE Transactions on Antennas and Propagation 2012 (accepted). 